\title{
Performance of Novel Engineered Materials from Epoxy Resin with Modified Epoxidized Natural Rubber and Nanocellulose or Nanosilica
}

\author{
Aunnuda Lanna, ${ }^{1}$ Montri Suklueng, ${ }^{2}$ Chainuson Kasagepongsan, ${ }^{3}$ and Sunisa Suchat $\mathbb{D}^{1}$ \\ ${ }^{1}$ Faculty of Sciences and Industrial Technology, Prince of Songkla University, Surat Thani Campus, P.O. Box 8, Khuntalea Post Office, \\ Muang District, Surat Thani 84100, Thailand \\ ${ }^{2}$ Energy Systems Research Institute (PERIN), Prince of Songkla University, Hatyai Campus, Songkhla 90110, Thailand \\ ${ }^{3}$ Department of Physics, Faculty of Science and Technology, Suratthani Rajabhat University, Surat Thani 84100, Thailand \\ Correspondence should be addressed to Sunisa Suchat; sunisa.su@psu.ac.th
}

Received 28 July 2019; Revised 3 September 2019; Accepted 12 September 2019; Published 10 January 2020

Academic Editor: Fabien Salaün

Copyright (c) 2020 Aunnuda Lanna et al. This is an open access article distributed under the Creative Commons Attribution License, which permits unrestricted use, distribution, and reproduction in any medium, provided the original work is properly cited.

\begin{abstract}
Performance of new engineered material from epoxy resins with modified epoxidized natural rubber (ENR) and nanofillers were investigated. ENR from renewable natural crop resources is a type of green material with potential to partially substitute or replace and toughen petrochemical-based polymers. Nanocomposites (epoxy resin/ENR/fillers nanoparticles) were characterized with Fourier transform infrared spectroscopy (FTIR), dynamic light scattering (DLS), atomic force microscope (AFM), and scanning electron microscopy (SEM). Comparison of characterized and mechanical properties of nanofiller reinforced with both nanocellulose and nanosilica were studied. The nanocomposites were characterized for their mechanical properties (e.g., impact strength, tensile strength) and thermal degradation behaviour by thermal gravimetric analysis (TGA). Mechanical property investigation results show that, the impact strength of nanocomposites, can be improved by blending in ENR 50 mixed with nanofiller, relative to the baseline nanocomposite mixers. The nanofiller loading in epoxy composite showed the highest improvement in mechanical properties at $0.75 \mathrm{phr}$ (parts per hundred of resin). Effects of accelerated weathering aging were evaluated, and the observed changes were larger with nanosilica than with nanocellulose filler. Here, the accelerated aging increase in tensile properties was found to be $10 \%$ after 14 days in both nanofillers, while the other mechanical properties did not change significantly. These nanocomposites are expected to have high wear rates limiting their service life.
\end{abstract}

\section{Introduction}

Nowadays, quality assurance, health protection, and environmental preservation have become interdependent and interrelated aspects and are considered to be the primary factors that respond to the concept of sustainable development. The methods used to manufacture propeller blades need to be green and environmentally friendly [1]. An epoxy composite has a major focus for Unmanned Aerial Vehicle (UAV) blades manufacturers. In this perspective, the outcomes presented in this paper can be exploited in modern blade with the aim to develop reliable, efficient and cost-effective blades that can withstand, without adverse effects, severe static and/or dynamic loadings, to which they may be exposed during their lifetime.
To enable sustainable production of nanocomposite blades coupled with green manufacturing practices, designers, and users should innovate on how to integrate health and environmental aspects into the bonding procedures. The present investigation to develop a new approach providing high performance adhesively-bonded composite blade half-shells in terms of Quality-Health-Environment related issues. Alternative solutions leading to a new generation of environmentally-friendly products can be achieved through the integration of a new green material factor into the classical bonding formulations. The blades are mostly made of nanosilica, carbon fiber, and fiber glass because these are strong but lightweight $[1,2]$. However, epoxy resins are the most important component in these composites, used as the adhesive 


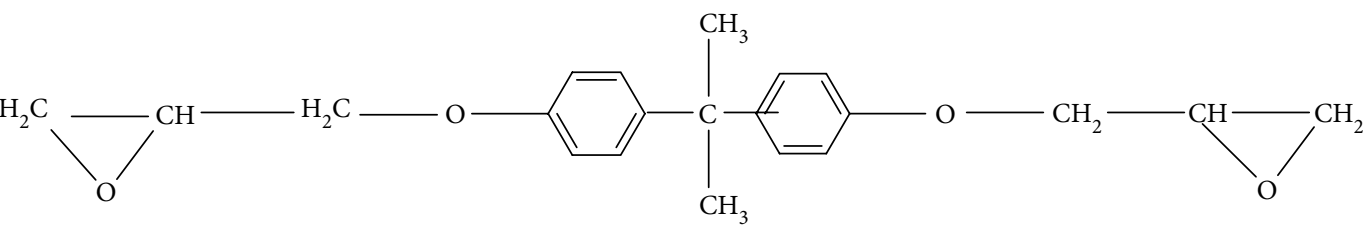

(a)<smiles>Cc1ccc(N)cc1Cl</smiles>

(b)

FIGURE 1: The chemical structure of: (a) bisphenol-A diglycidyl ether, and (b) polyamine.

matrix with the fibers for improved strength and smooth glossy surfaces. Improving the ductility of these blades for better impact resistance is desired. The materials conventionally used in the composite are epoxy resin, fiber, and hardener [1-3]. The main component is epoxy resin which is also used in a wide range of civil engineering applications. This is because epoxy resin has excellent bonding properties, and also after curing it has good mechanical properties (high modulus, low creep, and reasonable elevated temperature performance), but it easily fails under impact because of the highly crosslinked structure $[4,5]$. Elastomers materials that have been added to epoxy resin to improve its toughness include hard particulate materials [6,7]. In addition, modified epoxidized natural rubber (ENR) elastomers have been studied [1]. ENR was synthesized from natural rubber (NR) [8], which is an important renewable resource. The challenges for commercialization of biobased engineered materials are assessed. Management concerns about material of renewable resources and climate change have resulted in attempts to find green alternatives for petroleum based materials and mitigate greenhouse gas emissions. ENR particles and other soft materials such as polysiloxane, have been studied to improve the fracture toughness of brittle epoxy resin $[9,10]$. Among the numerous attempts to enhance the impact strength of epoxy resin, blending in natural rubber or epoxidized natural rubber (ENR) latex has also been tested $[11,12]$. In that study, comparisons of degradation of the nanocomposites were carried out in one outdoor weathering test. Environmental aging is caused by humidity, wind, and ultraviolet radiation, causing irreversible changes in the molecular structure of materials and affecting their durability $[13,14]$. The tensile properties of epoxy resin composites may improve in the initial consolidation stage during aging, which is attributed to postcuring reactions [15]. A degradation stage follows the composite properties are significantly degraded. This is attributed to deterioration and weakening of the matrix interfaces [16]. The purpose of this study was to improve the critical mechanical properties of epoxy resin composites by adding ENR elastomer with nanofiller. The two types of nanofiller (nanosilica or nanocellulose) were tested at various filler loading levels to improve the mechanical properties for use in blades (wind turbine and UAV blade applications). Nanocomposites approaches to overcome epoxy brittleness and deal with ongoing research strategies to make tough biobased materials. The key toughening modifiers such as rubber, nanofillers are discussed. The challenges for commercialization of biobased modifiers are assessed of research and development of the tough engineered materials are explored.

\section{Materials and Methods}

\subsection{Materials}

2.1.1. Modified Epoxidized Natural Rubber (ENR). The ENR was synthesized from natural rubber (NR) latex, obtained from Muang Mai Guthrie Co., Ltd. Thailand. NR contained spherical particles with an average diameter around $1 \mu \mathrm{m}$, and its solid content was about $60 \mathrm{wt} \%$. The density of NR was $0.92 \mathrm{gcm}^{-3}$ and it contained more than $98 \%$ cis- 1,4 polyisoprene. The ENR 50 was prepared via in situ epoxidation to $50 \mathrm{~mol} \%$ epoxide content with performic acid epoxidation of natural rubber latex using $0.5 \mathrm{M}$ hydrogen peroxide, polyalcohol ethylene oxide condensate (Terric 16A-16) (3wt\%) and $0.75 \mathrm{M}$ reagent grade formic acid. The reaction was allowed to proceed at $50^{\circ} \mathrm{C}$ for $8 \mathrm{~h}[8]$.

2.1.2. Epoxy Resin (EP). The epoxy resin was used as bisphenol-A type epoxy resin, the chemical structure show in Figure 1(a) bisphenol-A diglycidyl ether (Epotec YD 535 LV: Epicholrohydrin-bisphenol A), average molecular weight less than $700 \mathrm{~g} / \mathrm{mol}$. The specific gravity of EP was 1.10 , and viscosity 1,200 cps, and purchased from Aditya Birla Chemical Industry Co., Ltd., Thailand.

2.1.3. Curing Agent. A polyamine (TH 7255) was curing agent, the chemical structure show in Figure 1(b), the reacts with bisphenol-A type epoxy resin to cure at room temperature with heat generation. The specific gravity of TH 7255 was 1.04, and viscosity $100 \mathrm{cps}$. The TH 7255 curing agent was supplied by Aditya Birla Chemical Industry Co., Ltd., Thailand.

2.1.4. Nanofillers. The fillers nanoscale obtaining nanocomposites were separate into two types, one based on nanocellulose compare with nanosilica, and more detail as;

(1) Nanocellulose. The white nanocellulose powder was a commercial product prepared from wood pulp. Weight average molecular weight of the nanocellulose was $14,700-27,850 \mathrm{~g} /$ mol, with specific surface area of $400 \mathrm{~m}^{2} / \mathrm{g}$. The nanocellulose was provided by CelluForce, Canada.

(2) Nanosilica. The nanosilica colloidal from white nanosilica powder was surface-modified with methyl triethoxy silane [17]. Weight average molecular weight of the nanosilica was $60 \mathrm{~g} / \mathrm{mol}$, with specific surface area of $135 \mathrm{~m}^{2} / \mathrm{g}$. The $40 \mathrm{wt} \%$ nanosilica colloidal was kindly suspension in $\mathrm{H}_{2} \mathrm{O}$, provided by Bossofticl Co., Ltd., Thailand. 
2.2. Nanocomposite Samples Preparation. The nanocomposites were prepared as follows.

First, the epoxy resin $100 \mathrm{phr}$ (phr: parts per hundred parts of epoxy resin) was blended with $5 \mathrm{phr}$ of $50 \mathrm{~mol} \%$ epoxide content of epoxidized natural rubber (ENR 50) and with desired nanofiller loading, stirring in the reactor (AM120Z-H Laboratory electric mixer/Stirring machine) for $15 \mathrm{~min}$ at $50 \mathrm{rpm}$, and at room temperature $\left(30^{\circ} \mathrm{C}\right)$. As the second step, the TH 7255 hardener or curing agent was stirred in at the same stirrer speed for $5 \mathrm{~min}$. Finally, the nanocomposites specimens were formed into rubber molds at room temperature for $24 \mathrm{~h}$, and the specimens formed with a computer molded numerical control (CNC) machine to samples prepared for mechanical properties tested.

2.3. Characterization and Analysis. The characterization of nanocomposites samples from epoxy resin blended with ENR 50 and nanofiller were done as follows.

\subsubsection{Fourier Transform Infrared Spectroscopy}

(FTIR). Approximately $15 \mathrm{mg}$ sample of the composite was subjected to Fourier transform infrared spectroscopy. To assess the functional groups in raw materials, each of samples were similarly studied by FTIR. The FTIR spectra were recorded using a Vertex 70, (Bruker, Karlsruhe, Germany), which was equipped with a germanium ATR crystal probe and allows direct recording of the spectra without sample preparation. The recorded spectra were averages of 32 scans over the wave number range $4000-400 \mathrm{~cm}^{-1}$ at $4 \mathrm{~cm}^{-1}$ resolution. A background scan of the clean crystal was recorded before scanning the samples.

2.3.2. Dynamic Light Scattering (DLS). Dynamic light scattering is a technique measuring the intensity of light, also known as photon correlation spectroscopy (PCS), that can estimate particle sizes in nanometer range: within $0.005-5$ micrometers. The measurements were done at room temperature in suspension mode using Annalys 22 Nanotech, Germany.

2.3.3. Atomic Force Microscope (AFM). An atomic force microscope was used to characterize the particle sizes of nanofillers. AFM images were captured at room temperature in semicontact mode using Nanosurf Easyscan 2 AFM (Nanosurf AG, Liestal, Switzerland).

2.4. Mechanical Properties. Key mechanical properties of the nanocomposites (epoxy resin blend with ENR 50 and nanofiller) for propeller blade applications were determined. The tensile strength according to ASTM D638, the impact strength was measured according to ASTM D256, and the hardness (Shore D) according to ASTM D2240.

2.4.1. Tensile Strength. The tensile strength of nanocomposites (epoxy resin with ENR 50 and nanofiller) were measured by Universal Testing Machine, Zwick Roll, Germany (Z010) according to ASTM D638. The testing machine was equipped with a $10 \mathrm{kN}$ load cell, and the extension speed used was $50 \mathrm{~mm} / \mathrm{min}$. The specimen's type I were prepared to $50 \mathrm{~mm}$ and $3 \mathrm{~mm}$ working and gauge lengths. The tensile strength is the maximal force per unit area acting on a plane transverse to the applied load, and is a fundamental measure of the internal cohesive forces within a sample.

2.4.2. Impact Strength. The Izod impact strengths of cured unnotched samples of nanocomposites (epoxy resin with ENR 50 and nanofiller) were measured. The energy absorbed in breaking the specimen can be expressed in SI units and was determined by the impact tester machine (Dynisco Polymer Test 50J, Japan). The Izod pendulum impact test records the energy to break standard test composite specimens of specified size under conditions stipulated by ASTM D256. The specimen dimensions were $63.5 \mathrm{~mm} \times 12.7 \mathrm{~mm} \times 3.0 \mathrm{~mm}$ $[1,3]$. The sample is held in a cantilevered beam configuration (opposed to a three-point bending configuration).

2.4.3. Hardness. The hardness of nanocomposite was measured with digital hardness durometer Shore D meter. Specimens were at least $6.0 \mathrm{~mm}(0.25$ inches $)$ thick, and one specimen of each type was measured three times replicates. The measuring the initial hardness, or the indentation hardness after a given period of time. The test requires applying mechanical force in a consistent manner.

2.5. Morphological Typology. Scanning electron microscope (SEM) is one of the common methods for imaging the morphology of the materials. SEM imaging was done in the vicinity of a razor notch, to reflect uniform failure mode. And also, SEM was to assess the phase compatibility in the nanocomposite. In SEM, an electron beam with low energy is radiated to the material and scans the surface of the sample. The SEM specimens were sputter coated $(5-8 \mathrm{kV}$ in a vacuum) with thin gold/palladium layer and were imaged with Cambridge Stereoscan 200 (FEI-Quanta 400, Jeol Ltd., Tokyo, Japan).

\subsection{Thermal Properties}

2.6.1. Thermogravimetric Analysis (TGA). Thermal properties were assessed with TGA (STA 6000, Perkin Elmer Inc., Connecticut, USA) over the temperature range from $30^{\circ} \mathrm{C}$ to $600^{\circ} \mathrm{C}$ with $\mathrm{N}_{2}$ and $600^{\circ} \mathrm{C}$ to $900^{\circ} \mathrm{C}$ with $\mathrm{O}_{2}$ flushing, with a heating rate of $10^{\circ} \mathrm{C} \mathrm{min}^{-1}$ and flow rate of $100 \mathrm{ml} / \mathrm{min}$, using about $10 \mathrm{mg}$ samples.

2.6.2. Accelerated Aging. The weathering with UVA exposure was performed following ASTM G154 cycle I, using a QUVaccelerated weathering tester (QUV test LU-0819, Q-panel lab products, USA). The conditions of QUV-accelerated weathering test include UVA radiation at $340 \mathrm{~nm}$ and $0.77 \mathrm{~W} / \mathrm{m}^{2}$ intensity, at $60^{\circ} \mathrm{C}$ for $8 \mathrm{~h}$, water-condensation at $50^{\circ} \mathrm{C}$ for 4 $\mathrm{h}$, and water sprayed on the specimen for $15 \mathrm{~min}$. The aging cycles were repeated for up to $168 \mathrm{~h}$ and $336 \mathrm{~h}$.

2.7. Statistical Analyses. The XLSTAT software of ANOVA was used to measure significance of factors on the mechanical properties. 
TABLE 1: Comparing the FTIR spectras of raw materials.

\begin{tabular}{|c|c|c|c|c|c|}
\hline \multirow{2}{*}{ Functional groups } & \multicolumn{5}{|c|}{ Wavenumber $\left(\mathrm{cm}^{-1}\right)$} \\
\hline & Epoxy resin & NR & ENR 50 & Nanocellulose & Nanosilica \\
\hline $\mathrm{C}-\mathrm{O}$ deformation of the oxirane group & 915 & - & - & - & - \\
\hline Stretching of $\mathrm{C}-\mathrm{H}$ of the oxirane ring & 3057 & - & - & - & - \\
\hline $\mathrm{C}=\mathrm{C}-\mathrm{H}$ & - & 838,1660 & 837,1588 & - & - \\
\hline $\mathrm{C}-\mathrm{O}$ stretching of oxyran ring & - & - & 873 & - & - \\
\hline $\mathrm{C}=\mathrm{O}$ stretching & - & - & - & 1730 & - \\
\hline $\mathrm{C}-\mathrm{O}$ stretching vibration of hemicellulose & - & - & - & 1246 & - \\
\hline $\mathrm{C}=\mathrm{C}$ stretching of aromatic ring in lignin & - & - & - & 1506 & - \\
\hline $\mathrm{C}-\mathrm{O}-\mathrm{C}$ glycosidic linkages between glucose units in cellulose & - & - & - & 897 & - \\
\hline $\mathrm{H}-\mathrm{O}-\mathrm{H}$ stretching mode of the absorbed water & - & - & - & 3400 & 3340,1645 \\
\hline $\mathrm{Si}-\mathrm{O}-\mathrm{Si}$ asymmetric bond $(\mathrm{Si}-\mathrm{O})$ & - & - & - & - & 1093 \\
\hline $\mathrm{Si}-\mathrm{O}-\mathrm{Si}$ asymmetric bond $(\mathrm{Si}-\mathrm{OH})$ & - & - & - & - & 788 \\
\hline $\mathrm{Si}-\mathrm{O}-\mathrm{Si}$ bond bending vibration ( $\mathrm{Si}-\mathrm{O}-\mathrm{Si}$, siloxane) & - & - & - & - & 466 \\
\hline
\end{tabular}

\section{Results and Discussion}

3.1. Characterization of Materials. The first step in assessing of nanocomposites materials is to chemically identify and characterize materials.

3.1.1. Particle Size of Nanofiller. The particle size distributions are shown in Figure 2(a) (for nanocellulose), and Figure 2(b) (for nanosilica). Dynamic light scattering provides quick, precise and repeatable nanoparticle size data and it is an essential tool for the nanoparticle technologist. The $\mathrm{z}$-average diameters obtained with the SZ-100 are listed. The size distribution of nanocellulose is bimodal with two peaks (Figure 2(a)). There is nanocellulose diameter of particles at which exactly $90 \%$ of particle volume is larger than $20.3 \mathrm{~nm}$, and $10 \%$ of particles smaller than about $1.4 \mathrm{~nm}$. Figure 2(b) show that the particle size distribution of nanosilica is unimodal with nominal particle size around $20 \mathrm{~nm}$ and average diameter around $50 \mathrm{~nm}$.

The particle size of nanofiller can be confirmed by an atomic force microscope (AFM) in Figures 2(a)(1)-2(a)(3) for nanocellulose, and Figures 2(b)(1)-2(b)(3) for nanosilica show topographies with nanofiller in 2-D and 3-D images, and these clearly allow distinguishing nanoparticles.

The average particle sizes were estimated as $20.34 \mathrm{~nm}$ for nanocellulose and $52.8 \mathrm{~nm}$ for nanosilica, by image analysis.

\subsubsection{Fourier Transform Infrared Spectroscopy (FTIR)}

Analysis. The FTIR spectra in the range $4000-400 \mathrm{~cm}^{-1}$ are summarized in Table 1 and shown in Figure 3. The first line (Epoxy resin line) at $915 \mathrm{~cm}^{-1}$ is attributed to $\mathrm{C}-\mathrm{O}$ deformations in the oxirane group $[8,18]$. The peak at approximately $3050 \mathrm{~cm}^{-1}$ is attributed to $\mathrm{C}-\mathrm{H}$ stretching in the methylene group of epoxy ring. This peak is polymerization degree epoxy monomers it can be used as a qualitative indicator of the presence of epoxy groups. The FTIR spectrum of NR (NR lines) shows strong peaks of unsaturated $\mathrm{C}=\mathrm{C}$ stretching at $1660 \mathrm{~cm}^{-1}$. Peaks at $2935 \mathrm{~cm}^{-1}, 2864 \mathrm{~cm}^{-1}$, and $2840 \mathrm{~cm}^{-1}$ attributed to $\mathrm{C}-\mathrm{H}$ stretching and the peak at $837 \mathrm{~cm}^{-1}$ indicating $\mathrm{C}-\mathrm{H}$ bending attached to unsaturated carbon $[19,20]$. For the ENR 50 line appeared peaks at $870 \mathrm{~cm}^{-1}$ indicate the epoxy ring and $\mathrm{C}-\mathrm{H}$ bending attached to the oxyrane ring, the intensities at $838 \mathrm{~cm}^{-1}$ which are observed in ENR 50 reduced after epoxidation increased, which might be due to the epoxy ring has also occurred at the $\mathrm{C}=\mathrm{C}$ double bond [21]. The absorption band approximately $1730 \mathrm{~cm}^{-1}$ in the nanocellulose spectrum (Nanocellulose line) is due to $-\mathrm{C}=\mathrm{O}$ stretching in carboxylic acid or ester groups, seen in Figure 3. The peak at $897 \mathrm{~cm}^{-1}$ was assigned to $\mathrm{C}-\mathrm{O}-\mathrm{C}$ glycosidic linkages between glucose units in cellulose, while absorption at $3440 \mathrm{~cm}^{-1}$ was assigned to $\mathrm{H}-\mathrm{O}-\mathrm{H}$ stretching. At $1506 \mathrm{~cm}^{-1}$ the absorption band is due to stretching of special types of unsaturation in the benzene ring. The absorption at $1246 \mathrm{~cm}^{-1}$ is related to $(\mathrm{C}-\mathrm{O})$ stretching. The FTIR results confirm the three main characteristic peaks of nanosilica (Nanosilica lines) from $\mathrm{Si}-\mathrm{O}-\mathrm{Si}$ asymmetric bond $(\mathrm{Si}-\mathrm{O})$ at $1093 \mathrm{~cm}^{-1}, \mathrm{Si}-\mathrm{O}-\mathrm{Si}$ asymmetric bond $(\mathrm{Si}-\mathrm{OH})$ at $788 \mathrm{~cm}^{-1}$ and $\mathrm{Si}-\mathrm{O}-\mathrm{Si}$ bond bending vibrations $(\mathrm{Si}-\mathrm{O}-\mathrm{Si}$, siloxane) at $466 \mathrm{~cm}^{-1}$; these are attributed to asymmetric and symmetric stretching, and bending modes of silica, respectively. The absorption bands at $3440 \mathrm{~cm}^{-1}$ and $1645 \mathrm{~cm}^{-1}$ were assigned to $\mathrm{H}-\mathrm{O}-\mathrm{H}$ stretching and bending modes of adsorbed water, respectively, related to the silanol-OH groups and water bound to silica surfaces [17]. These spectra for the composites $(\mathrm{EP}+\mathrm{ENR} 50, \mathrm{EP}+\mathrm{ENR} 50+\mathrm{CNC}$, and $\mathrm{EP}+\mathrm{ENR} 50+$ Nanosilica) had absorption at $915 \mathrm{~cm}^{-1}$, which is attributed to $\mathrm{C}-\mathrm{O}$ deformations in oxirane group, and at $3050 \mathrm{~cm}^{-1}$ that is attributed to $\mathrm{C}-\mathrm{H}$ stretching in methylene group of the epoxide rings.

FTIR has been used to identify the level of $50 \mathrm{~mol} \%$ epoxidation in ENR $[1,8]$. The ENR 50 usually has high elasticity, and resilience strain crystallization, but low oil resistance in the latex stage. Accordingly, this ENR was labelled ENR 50 as in prior work.

\subsection{Morphology of Nanocomposite}

\subsubsection{Morphology of the Epoxy without and with ENR}

50. Morphology was assessed from SEM micrographs of notched Izod impact fracture surfaces (Figure 4(a)) for the neat epoxy resin matrix and the related composites. The structural investigation of the fracture surfaces were showed the formation of new phases on the surfaces of ENR 50 particles (Figure 4(b)). 


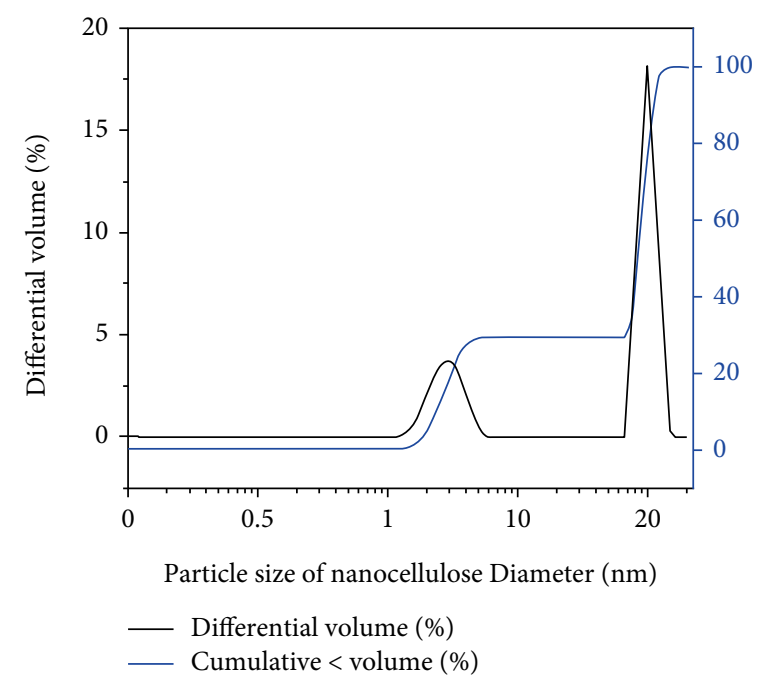

(a)

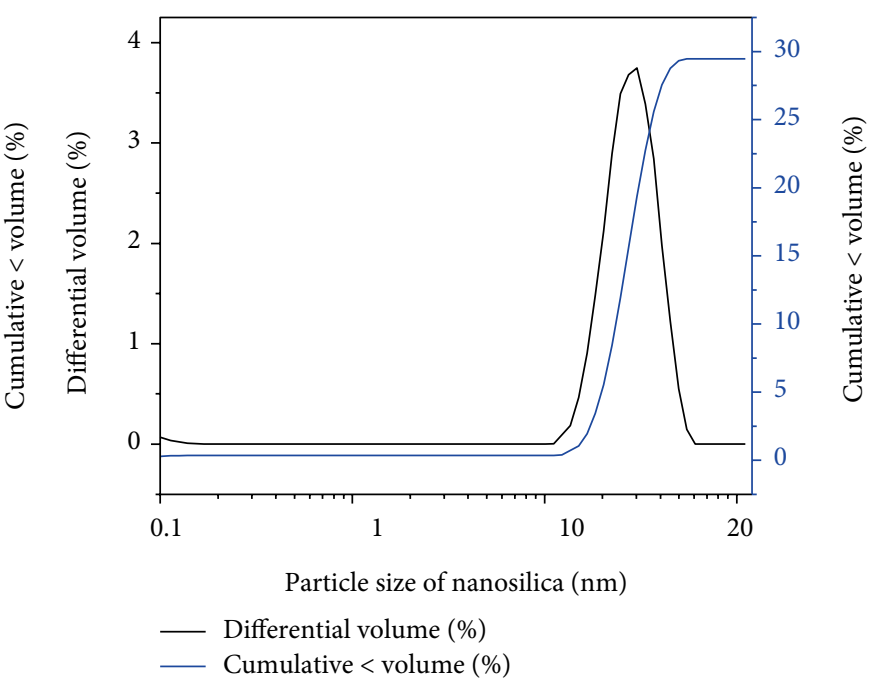

(b) (a)(1) Z-Axis - Scan forward Line fit
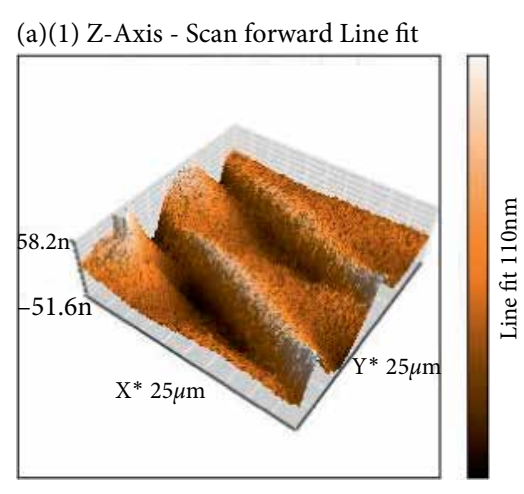

(a)(2) Z-Axis - Scan forward Line fit

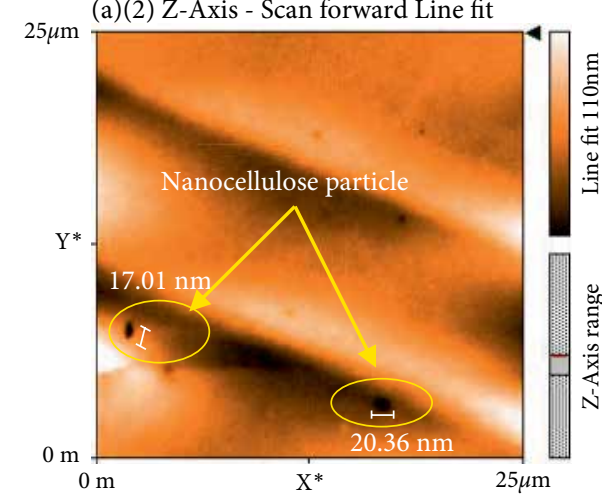

(b)(2) Z-Axis - Scan forward Line fit

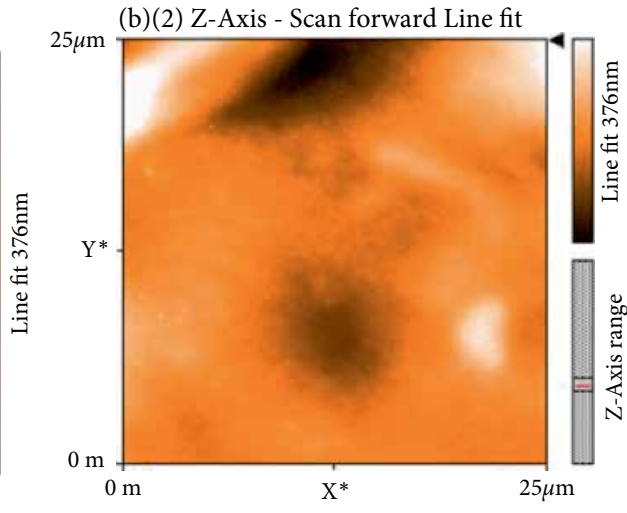

(a)(3) Amplitude - Scan forward Line fit

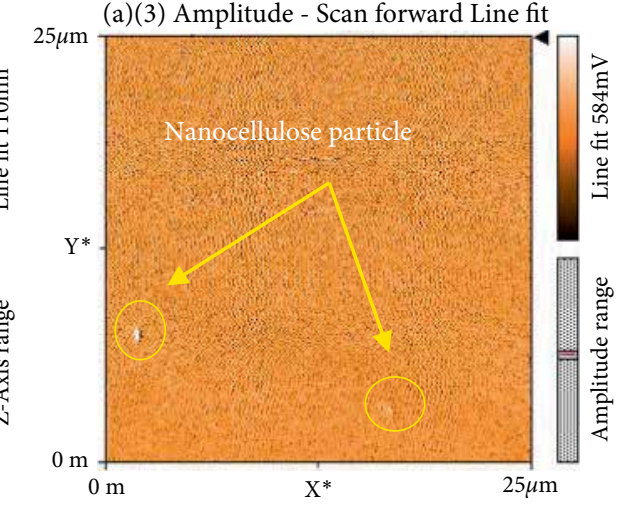

(b)(3) Amplitude - Scan forward Line fit

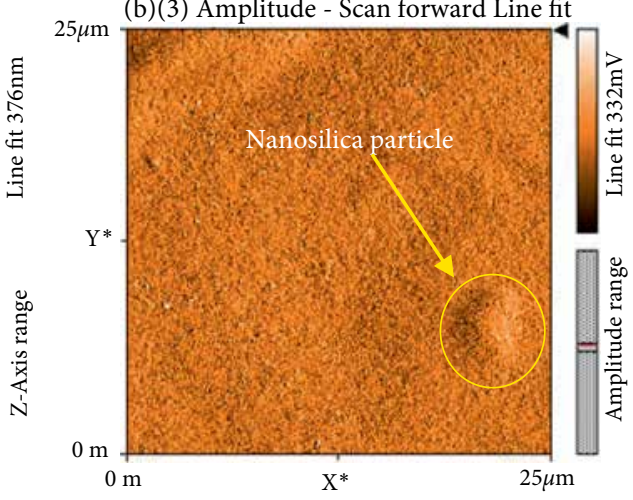

(b)(1) Z-Axis - Scan forward Line fit

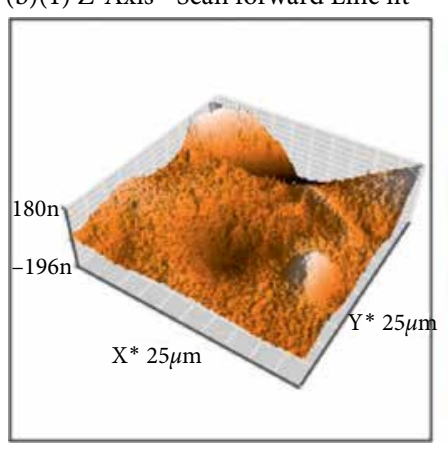

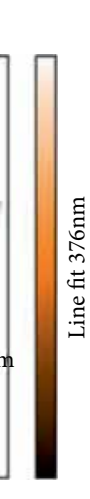

FIGURE 2: Particle size of nanofiller by dynamic light scattering and AFM images in topography of nanofiller, (a) nanocellulose, and (b) nanosilica; images in topography: (1) 3-D topography images of nanofiller, (2) phase 2-D of nanoparticles and (3) phase separate of nanoparticles.

The globular rubber nodules were improved impact strength and tensile strength. The epoxy resin and ENR 50 composite had better interactions at phase boundaries in the case of ENR 50, which gave higher impact strength than the neat epoxy resin matrix.

The rubber is present as the component, large globular domains dispersed in the thermoplastic are observed. The loading with $5 \mathrm{phr}$ of ENR 50 is an appropriate choice to improve impact strength. Amorphous ENR 50 was chosen for the model matrix to investigate the effects of the nanoparticles on mechanical properties of nanocomposites.

3.2.2. Morphology of Nanocomposites. Morphology of nanocomposites with epoxy resin, ENR 50 and nanofiller are shown in Figures 4(c) and 4(d), in SEM micrographs of notched Izod impact fracture surfaces. The micrograph of epoxy nanocomposite has smooth and glossy exterior with numerous wavy or stream-like cracks, shown by arrows. 


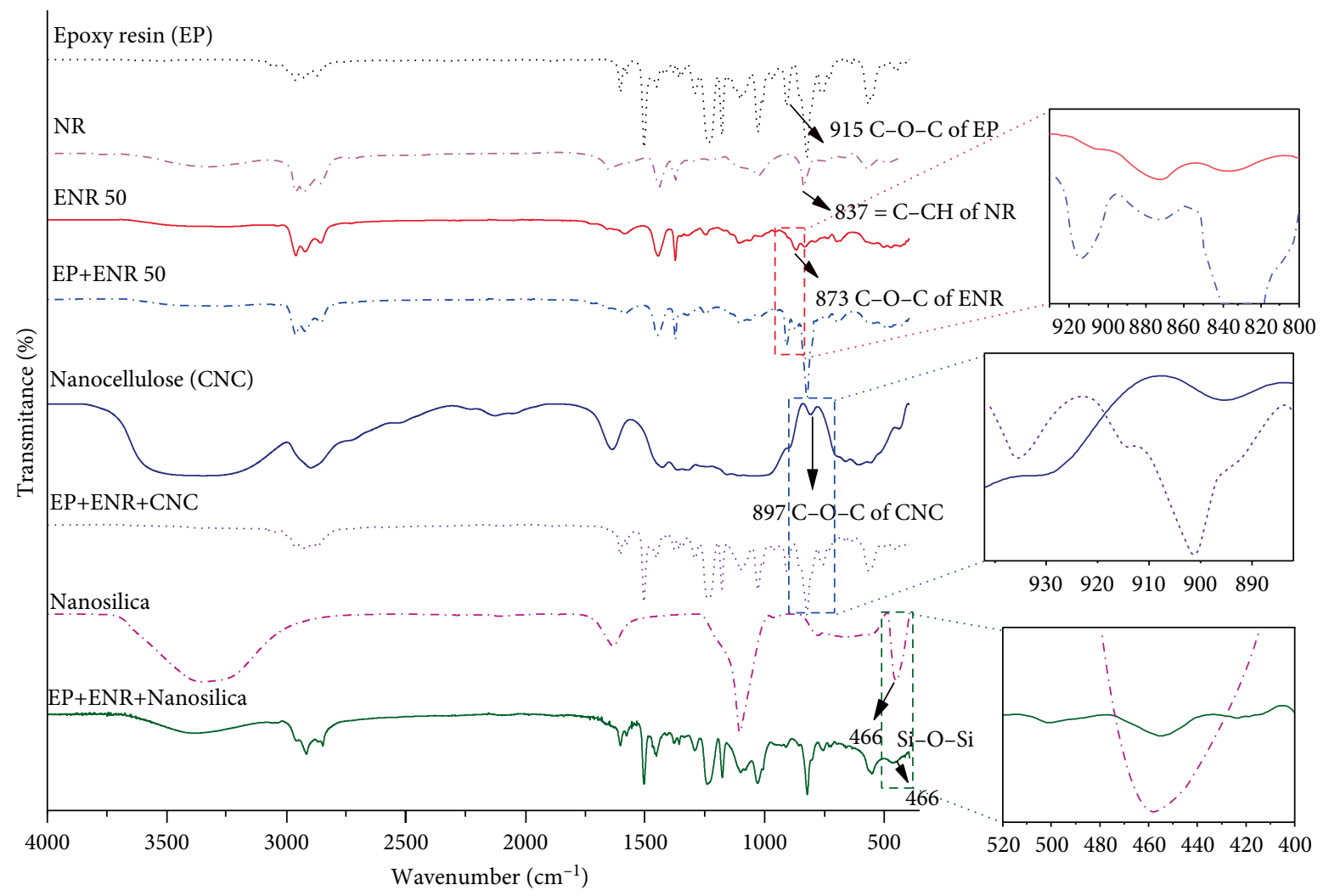

FIGURE 3: The FTIR spectra of various types of composites materials.

TABLE 2: Comparison of the mechanical properties of nanocomposites by type and loading of nanofiller.

\begin{tabular}{|c|c|c|c|c|c|c|}
\hline \multirow{2}{*}{$\begin{array}{l}\text { Nanofiller loading } \\
\text { (phr) }\end{array}$} & \multicolumn{2}{|c|}{ Impact strength $\left(\mathrm{kJ} / \mathrm{m}^{2}\right)$} & \multicolumn{2}{|c|}{ Hardness (shore D) } & \multicolumn{2}{|c|}{ Tensile strength (MPa) } \\
\hline & Nanocellulose & Nanosilica & Nanocellulose & Nanosilica & Nanocellulose & Nanosilica \\
\hline 0 & $6.50 \pm 0.75^{\mathrm{d}}$ & $6.50 \pm 0.75^{\mathrm{c}}$ & $65.67 \pm 0.90^{\mathrm{a}}$ & $65.67 \pm 0.90^{\mathrm{d}}$ & $35.40 \pm 1.00^{\mathrm{b}}$ & $35.40 \pm 1.00^{\mathrm{a}}$ \\
\hline 0.25 & $8.01 \pm 0.36^{\mathrm{c}}$ & $4.84 \pm 0.54^{\mathrm{d}}$ & $52.00 \pm 0.50^{c}$ & $71.67 \pm 0.63^{c}$ & $25.69 \pm 1.07^{\mathrm{c}}$ & $20.09 \pm 0.75^{\mathrm{d}}$ \\
\hline 0.5 & $11.50 \pm 0.69^{\mathrm{b}}$ & $8.02 \pm 0.44^{\mathrm{c}}$ & $53.33 \pm 0.58^{\mathrm{c}}$ & $74.17 \pm 1.04^{\mathrm{b}}$ & $33.10 \pm 1.21^{\mathrm{b}}$ & $29.54 \pm 1.08^{\mathrm{c}}$ \\
\hline 0.75 & $14.94 \pm 0.30^{\mathrm{a}}$ & $11.55 \pm 0.58^{\mathrm{b}}$ & $62.17 \pm 1.02^{\mathrm{b}}$ & $76.33 \pm 0.57^{\mathrm{a}}$ & $39.22 \pm 1.09^{\mathrm{a}}$ & $33.10 \pm 0.70^{\mathrm{b}}$ \\
\hline 1.00 & $13.05 \pm 0.54^{\mathrm{a}}$ & $13.70 \pm 0.35^{\mathrm{a}}$ & $65.5 \pm 0.50^{\mathrm{a}}$ & $76.83 \pm 0.02^{\mathrm{a}}$ & $24.63 \pm 1.49^{c}$ & $35.48 \pm 1.10^{\mathrm{a}}$ \\
\hline
\end{tabular}

${ }_{\mathrm{a}, \mathrm{b}, c, \mathrm{~d}}$ Different superscripts indicate statistically significant differences at $95 \%$ confidence by Duncan's method. Mean \pm SD: mean and standard deviation based on triplicate samples.

There is a gradual increase in the yield strength of the rubber and nanofiller filled nanocomposite. Figure 4(c)(1-4) shows the nanocomposites blends of epoxy resin (EP)/ENR 50/ nanocellulose (CNC) with superior interactions at phase boundaries in the case of CNC at $0.75 \mathrm{phr}$, which gave the highest impact strength. The blend EP/ENR 50/nanosilica in Figure $4(\mathrm{~d})(1-4)$ had improved interactions at the phase boundaries of nanosilica, so the mechanical properties improved with nanofiller loading. The trends with nanosilica were similar to those with nanocellulose. The well dispersed nanocellulose and nanosilica in epoxy composite improved the mechanical properties. Increasing the nanofiller loading level continuously improved strength and fracture toughness. Overall, nanofillers are a promising approach to modify the properties of aerospace epoxy resin nanocomposites. It can be concluded that $0.75 \mathrm{phr}$ nanocellulose in the mixture was the best choice, with good compatibility and high strength without significant negative effects. It should be noted that adding more than 0.75 phr can worsen the mechanical properties.

3.3. The Mechanical Properties of Nanocomposites. To evaluate the mechanical properties of epoxy resin nanocomposites containing ENR 50 (ENR 50 at 5 phr loading improved the impact strength), and nanofiller. The nanofiller loading was varied up to 1 phr relative to the neat epoxy resin matrix, and results for the nanocomposites are collected in Table 2, showing that the nanofiller loading level affected the mechanical properties. In this investigation, we studied the effects of filler types and amounts for nanocellulose and nanosilica in composites. The impact strengths of the nanocomposites with $0.25,0.5,0.75$, and $1 \mathrm{phr}$ nanofiller loading levels were determined. The impact strength with 0.75 phr was higher than 


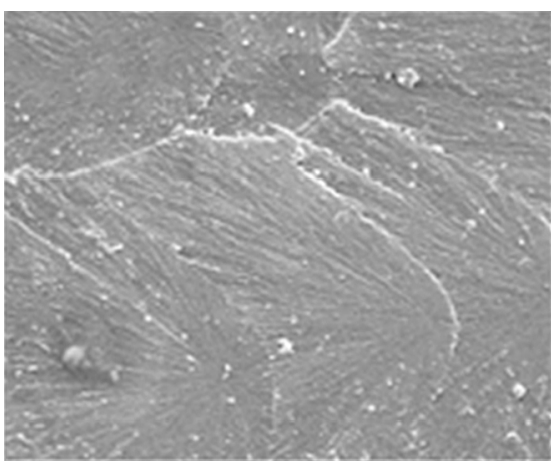

(a)

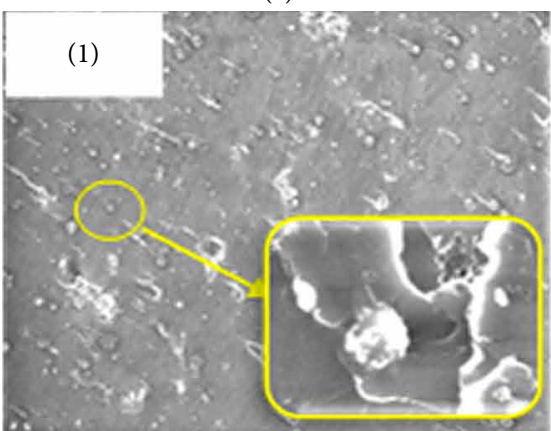

(2)
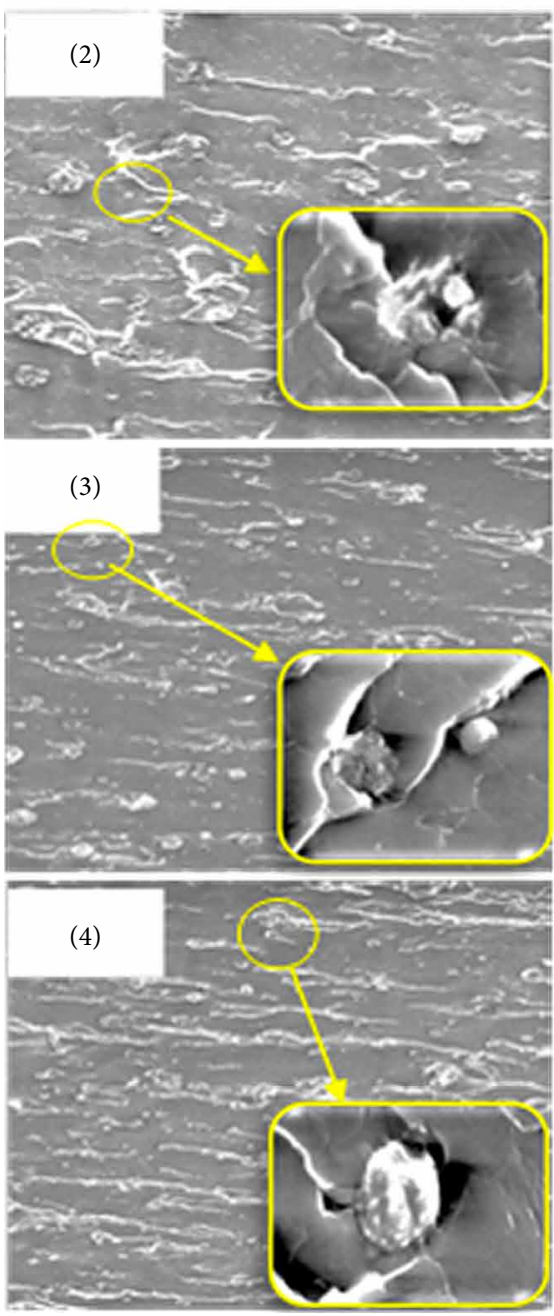

(c)

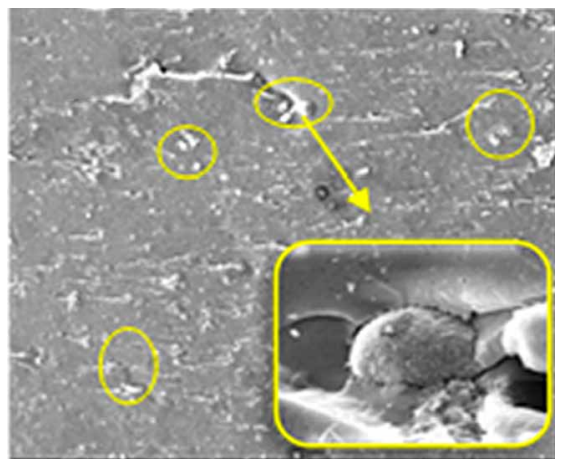

(b)

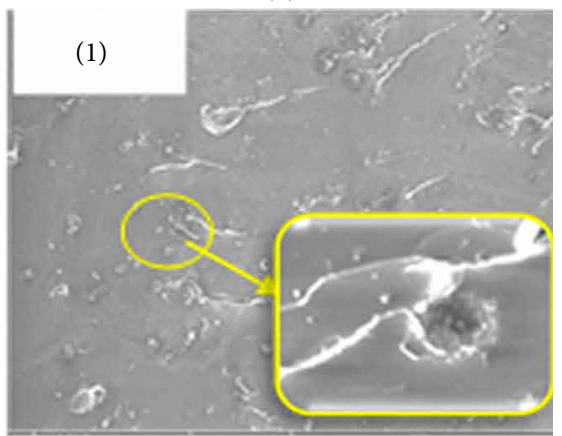

(2)
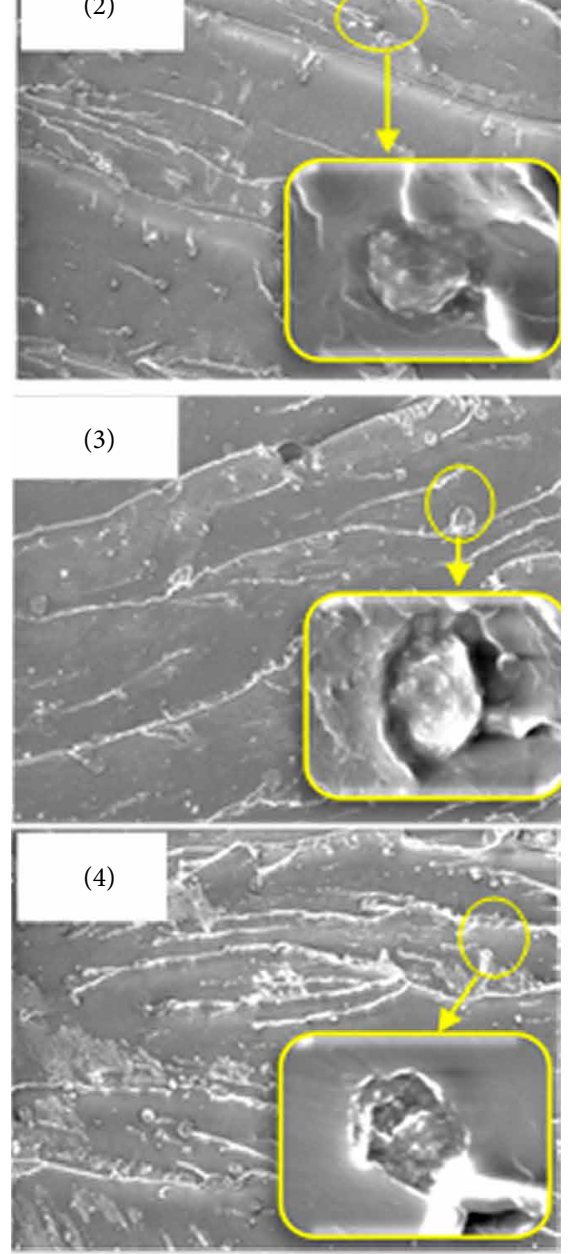

(d)

FIGURE 4: SEM micrographs of; (a) epoxy resin, (b) epoxy resin /5 phr ENR 50, and nanocomposite: 2 types of nanofillers: (c) nanocellulose, and (d) nanosilica, on nanofiller amounts: (1) $0.25 \mathrm{phr}$, (2) $0.5 \mathrm{phr}$, (3) $0.75 \mathrm{phr}$, and (4) $1.00 \mathrm{phr}$. 


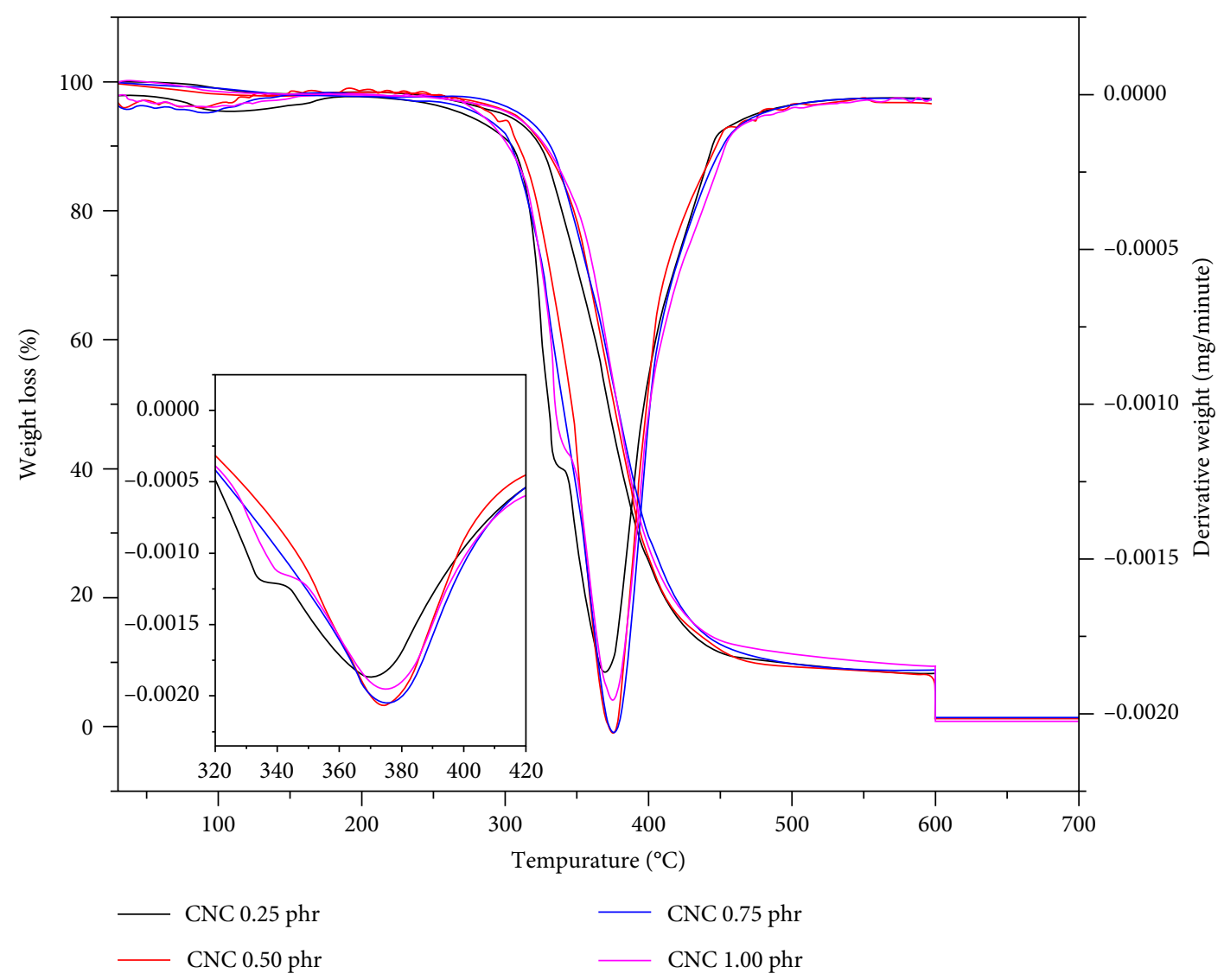

(a)

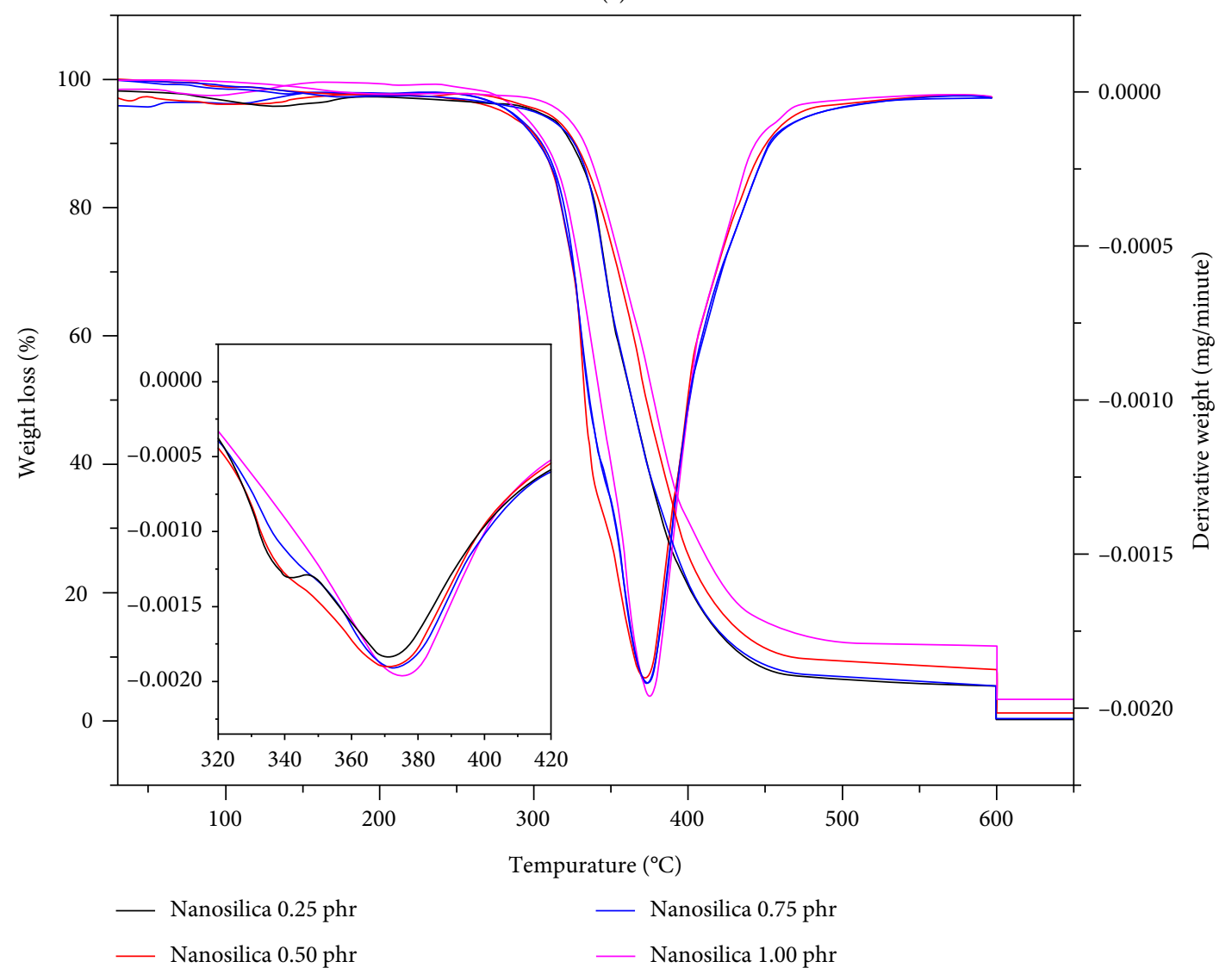

(b)

Figure 5: Thermal degradation by TGA of nanocomposites : (a) nanocellulose, (b) nanosilica. 


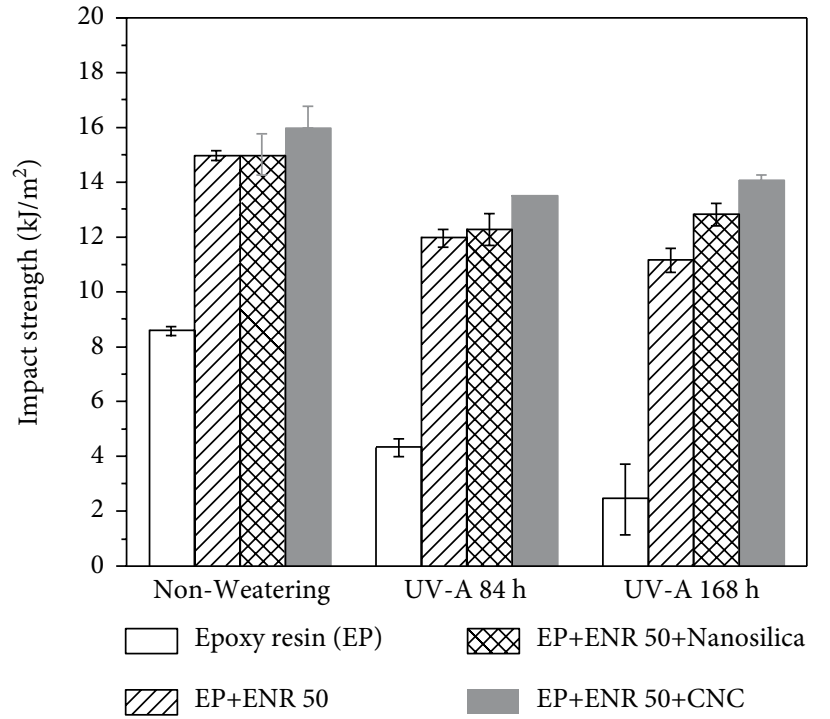

(a)

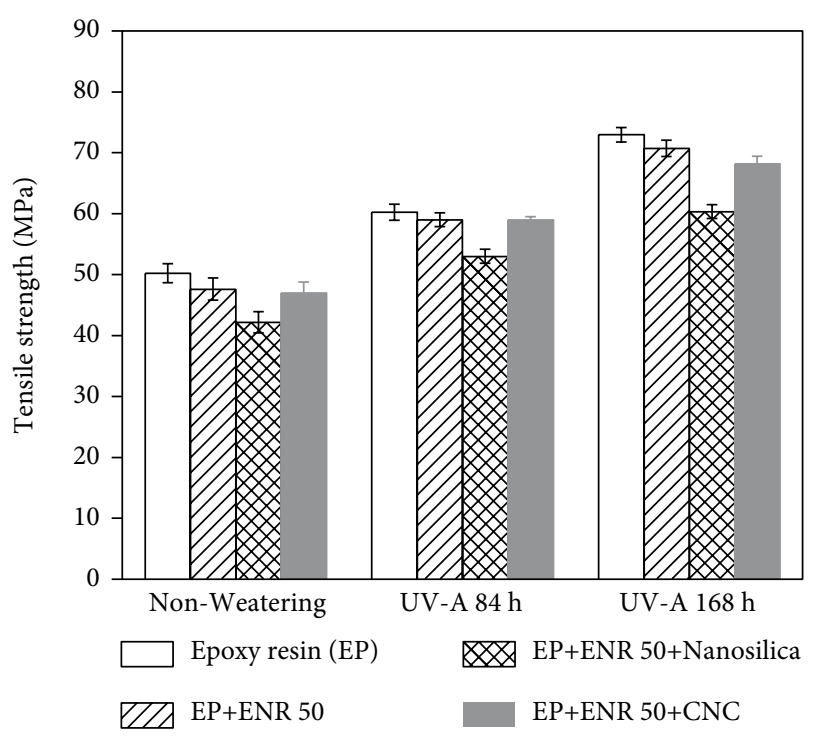

(b)

FIGURE 6: The mechanical properties of before and after accelerated aging of nanocomposites: (a) impact strength, and (b) tensile strength.

with $0.25,0.5$, and $1 \mathrm{phr}$. This is due to the small particle size of nanocellulose along with its good compatibility and dispersion in the epoxy matrix. The uniform dispersion and high aspect ratio of the nanocellulose contributed to good results with it, according to prior research $[22,23]$. The nanofillers were compatible with epoxy resin due to similar polarization levels, which improved stiffness of the nanocomposites.

Comparison of the types of nanofiller (nanocellulose and nanosilica) was done for finding the best mechanical properties of nanocomposites. Table 2 summarizes the mechanical properties, such as impact strength, tensile strength, and hardness that improved with nanofiller loading. Regarding tensile strength, nanocellulose increased it more than nanosilica, because the $\mathrm{C}-\mathrm{C}$ bonds with nanocellulose inhibit crystallization of rubber more than nanosilica. Also the impact strength with nanocellulose was higher than with nanosilica, possibly because the fibers improved resistance against crack propagation. There were no significant changes in the toughness, although it appeared higher for epoxy resin blends with nanosilica than with nanocellulose. The $\mathrm{SiO}_{2}$ bonded stronger than $\mathrm{C}-\mathrm{C}$ bonds, formerly hardness of nanosilica increased it more than nanocellulose. It was also found that regardless of the mixing approach, the strength of a nanocomposite having nanosilica or nanocellulose was higher than that of neat epoxy resin composite. Comparing the mechanical properties such as impact strength and tensile strength between filler loadings, it seems that the composite with $0.75 \mathrm{phr}$ nanocellulose would be the best choice with highest strength. However, nanocellulose as reinforcing filler gave even better mechanical properties than nanosilica. And the mechanical properties of nanocomposites were further improved by post cure during accelerated aging.

\subsection{Thermal Properties of Nanocomposites}

3.4.1. Thermogravimetric Analysis (TGA). It was used to study the thermal stability of the epoxy nanocomposites, Figures 5(a) and 5(b). The TGA thermograms show that the thermal stability of epoxy matrix steadily increased significantly with nanofiller loadings among $0.25,0.5,0.75$, and $1 \mathrm{phr}$. It is noted that, the TGA was performed under nitrogen atmosphere in the temperature range from 30 to $600^{\circ} \mathrm{C}$, and under oxygen atmosphere in the temperature range from 600 to $900^{\circ} \mathrm{C}$. Figure 5, two decomposition steps are clearly observed. The first step is for degradation under nitrogen atmosphere, and the second step is for decomposition under oxygen atmosphere. It is observed that while the thermal stability of nanocellulose (CNC)-nanocomposite in Figure 5(a) significantly improved, the maximum degradation temperature $\left(\mathrm{T}_{\mathrm{d}}\right)$ was around $370^{\circ} \mathrm{C}$ for all cases. However, the case with $0.75 \mathrm{phr} \mathrm{CNC}$ had the best thermal stability. Figure 5(b), it is observed that the thermal stability of nanosilica- nanocomposite significantly increased with nanosilica loading, but the maximum degradation temperature was $380^{\circ} \mathrm{C}$ for all cases. At the final $600^{\circ} \mathrm{C}$ temperature, the fillers (nanocellulose and nanosilica) in the composites might be partly decomposed in the second step and some residue still remained, and its amount tended to increase with filler. However, the overall stability of the nanocomposites depends greatly on the nature of crosslinks and nanofillers will have profound effects on the mechanical properties. In this study, the degree of crosslinking in the epoxy system was not evaluated, and it will be subjected to further investigation in the future.

3.4.2. The Accelerated Aging. The mechanical properties before and after accelerated aging of the optimal nanocomposites (100 phr epoxy resin, $5 \mathrm{phr}$ ENR 50 and $0.75 \mathrm{phr}$ nanofiller) are shown in Figure 6. The results show that the accelerated aging (UV-A for 68, 168, and 336h) reduced the impact strength in Figure 6(a), according to the Izod impact test. However, after accelerated aging the samples had increased hardness, and the surfaces of samples exhibited a distinct change in colour from colourless to dark yellow. Conversely, nanocellulose gave a higher impact strength than nanosilica. 
In Figure 6(b), show the accelerated aging improved tensile strength according previous researches [15], while the other mechanical properties did not change significantly. Effects of accelerated aging with UV-A were evaluated, and the observed changes were larger with nanosilica than with nanocellulose nanofiller. The nanocomposites had good strength properties after accelerated aging, and the best case was UV-A treatment for $168 \mathrm{~h}$. This is due to the small particle sizes of nanofiller and of ENR 50 that both had good compatibility and dispersion in the epoxy nanocomposites. When we compare between the types of nanofiller, nanocellulose gave higher tensile strength property than nanosilica. The high aspect ratio of nanocellulose fibers may help prevent crack propagation. Nanocomposites approach to engineered biobased epoxy resins with ENR and nanofillers fits the search for nonpetroleum-based structural materials, like bio-nanocomposites that are biodegradable, high performance and lightweight.

\section{Conclusions}

In this study, epoxidized natural rubber to $50 \mathrm{~mol}$ percent level at $5 \mathrm{phr}$ loading improved the impact strength of epoxy nanocomposite. Comparison of two types of nanofiller were applied and their effects on the mechanical properties before and after accelerated aging were assessed. Also morphology and thermal properties of the nanocomposites were examined. The optimum loading of nanosilica or nanocellulose for best overall performance was $0.75 \mathrm{phr}$. However, nanocellulose as reinforcing filler gave even better mechanical properties than nanosilica. Thermal stability improved with nanofiller loading. The nanocomposites had good strength properties also after accelerated aging. ENR 50 level at $5 \mathrm{phr}$ and nanocellulose at $0.75 \mathrm{phr}$ is a good choice of blend proportions to improve the impact resistance of epoxy resin nanocomposite, for use in blades propeller. Performance of new renewable materials from nanocomposites and agro-industrial is approaches to engineer tough biobased epoxy resin.

\section{Data Availability}

The data used to support the findings of this study are available from the corresponding author upon request.

\section{Conflicts of Interest}

The authors declare that they have no conflicts of interest.

\section{Acknowledgments}

This work was supported by the government budget of Prince of Songkla University with The Natural Rubber Innovation Research Institute of Prince of Songkla University with the funding number "SIT601019S" for financial support, the authors gratefully acknowledge the Research and Researcher for Industry Program with the funding number
“MSD60I0087”, Prince of Songkla University for financial support and the experiment station.

\section{References}

[1] N. Pithaksareetham, N. Hongkarnjanakul, and S. Suchat, "Econanocomposites with epoxidized natural rubber for improved mechanical properties essential to unmanned aerial vehicles propeller applications," Advances in Polymer Technology, vol. 37, no. 8, pp. 2946-2957, 2018.

[2] V. Jaiganesh and S. Manivannan, "Numerical analysis and simulation of nylon composite propeller for aircraft," Procedia Engineering, vol. 97, pp. 1079-1088, 2014.

[3] J. Jakobsen, M. Jensen, and J. H. Andreasen, "Thermo-mechanical characterisation of in-plane properties for CSM E-glass epoxy polymer composite materials-Part 1: thermal and chemical strain," Polymer Testing, vol. 32, no. 8, pp. 1350-1357, 2013.

[4] V. Trappe, S. Günzel, and M. Jaunich, "Correlation between crack propagation rate and cure process of epoxy resins," Polymer Testing, vol. 31, no. 5, pp. 654-659, 2012.

[5] J. Jakobsen, M. Jensen, and J. H. Andreasen, "Thermomechanical characterisation of in-plane properties for CSM E-glass epoxy polymer composite materials-Part 2: young's modulus," Polymer Testing, vol. 32, no. 8, pp. 1417-1422, 2013.

[6] E. Butta, G. Levita, A. Marchetti, and A. Lazzeri, "Morphology and mechanical properties of amine-terminated butadieneacrylonitrile/epoxy blends," Polymer Engineering \& Science, vol. 26, no. 1, pp. 63-73, 1986.

[7] J. H. Kim, B. R. Min, H. C. Park, J. Won, and Y. S. Kang, "Phase behavior and morphological studies of polyimide/PVP/solvent/ water systems by phase inversion," Journal of applied polymer science, vol. 81, no. 14, pp. 3481-3488, 2001.

[8] S. Suchat and W. Yingprasert, "ECO-adhesive from modified natural rubber for wood applications," Advanced Materials Research, vol. 844, pp. 182-185, 2014.

[9] F.-L. Jin and S.-J. Park, "Interfacial toughness properties of trifunctional epoxy resins/calcium carbonate nanocomposites," Materials Science and Engineering: A, vol. 475, no. 1-2, pp. 190-193, 2008.

[10] L. Guadagno, L. Vertuccio, A. Sorrentino et al., "Mechanical and barrier properties of epoxy resin filled with multi-walled carbon nanotubes," Carbon, vol. 47, no. 10, pp. 2419-2430, 2009.

[11] S. Chuayjuljit, N. Soatthiyanon, and P. Potiyaraj, "Polymer blends of epoxy resin and epoxidized natural rubber," Journal of Applied Polymer Science, vol. 102, no. 1, pp. 452-459, 2006.

[12] A. Lanna, N. Pithaksareetham, and S. Suchat, "Impact strength essential for UAV applications of epoxy resin blend improved with modified epoxidized natural rubber," in Proceedings of the Third Asia Pacific Rubber Conference (APRC), Surat Thani, Thailand, 2017.

[13] S.-G. Hong and C.-K. Chan, "The curing behaviors of the epoxy/ dicyanamide system modified with epoxidized natural rubber," Thermochimica Acta, vol. 417, no. 1, pp. 99-106, 2004.

[14] A. Mlyniec, J. Korta, R. Kudelski, and T. Uhl, “The influence of the laminate thickness, stacking sequence and thermal aging on the static and dynamic behavior of carbon/epoxy composites," Composite Structures, vol. 108, pp. 208-216, 2014.

[15] S. A. Awad, C. M. Fellows, and S. Saeed Mahini, "A comparative study of accelerated weathering of epoxy resins based on 
DGEBA and HDGEBA," Journal of Polymer Research, vol. 25, no. 4, pp. 103-110, 2018.

[16] B. Yang, J. Zhang, L. Zhou, M. Lu, W. Liang, and Z. Wang, "Effect of fiber surface modification on water absorption and hydrothermal aging behaviors of GF/pCBT composites," Composites Part B: Engineering, vol. 82, pp. 84-91, 2015.

[17] V. Jafari and A. Allahverdi, "Synthesis and characterization of colloidal nanosilica via an ultrasound assisted route based on alkali leaching of silica fume," International Journal of Nanoscience and Nanotechnology, vol. 10, no. 3, pp. 145-152, 2014.

[18] D. R. Burfield, K.-L. Lim, K.-S. Law, and S. Ng, "Analysis of epoxidized natural rubber. a comparative study of DSC, NMR, elemental analysis and direct titration methods," Polymer, vol. 25, no. 7, pp. 995-998, 1984.

[19] T. Saito, W. Klinklai, and S. Kawahara, "Characterization of epoxidized natural rubber by spectroscopy," Polymer, vol. 48, no. 3, pp. 750-757, 2007.

[20] T. Kochthongrasamee, P. Prasassarakich, and S. Kiatkamjornwong, "Effects of redox initiator on graft copolymerization of methyl methacrylate onto natural rubber," Journal of Applied Polymer Science, vol. 101, no. 4, pp. 2587-2601, 2006.

[21] M. Sasitarn, S. Manroshan, C. S. Lim, B. N. Kritsana, S. K. Ong, and R. Gunasunder, "Preparation and characterisation of crosslinked natural rubber (SMR CV 60) and epoxidised natural rubber (ENR-50) Blends," Journal on Science and Technology for Development, vol. 34, no. 2, pp. 106-118, 2017.

[22] Y. Zhang, P. Song, H. Liu, Q. Li, and S. Fu, "Morphology, healing and mechanical performance of nanofibrillated cellulose reinforced poly ( $\varepsilon$-caprolactone)/epoxy composites," Composites Science and Technology, vol. 125, pp. 62-70, 2016.

[23] P. Reis, J. Ferreira, P. Santos, M. Richardson, and J. Santos, "Impact response of kevlar composites with filled epoxy matrix," Composite Structures, vol. 94, no. 12, pp. 3520-3528, 2012. 


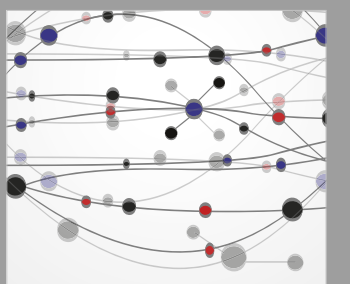

The Scientific World Journal
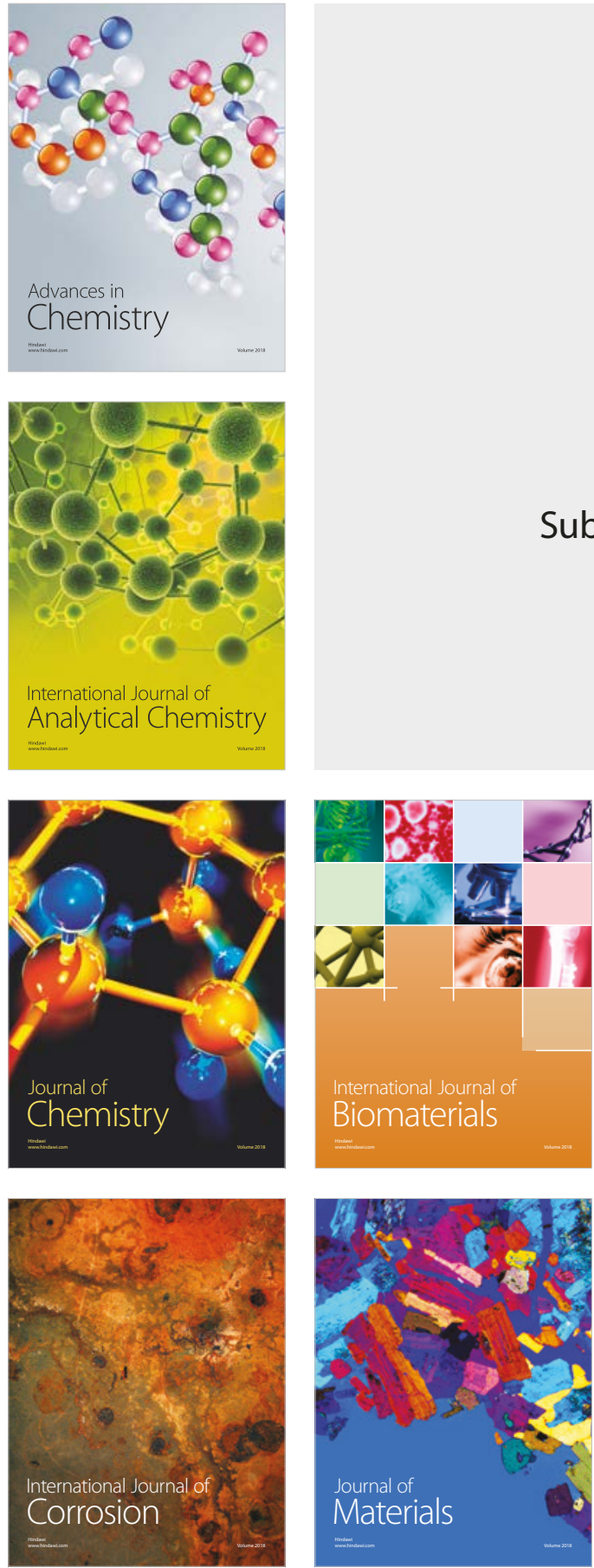

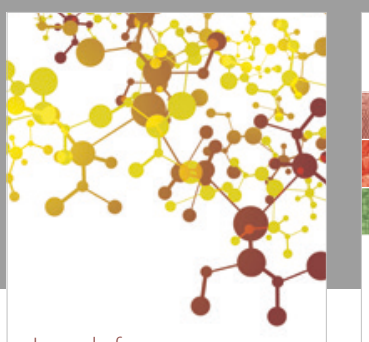

Journal of

Applied Chemistry
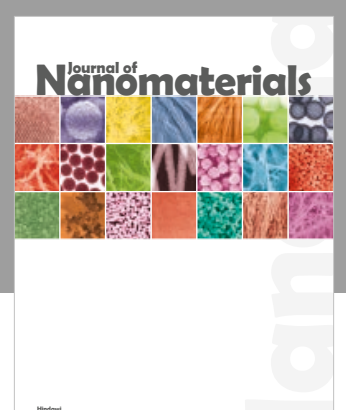

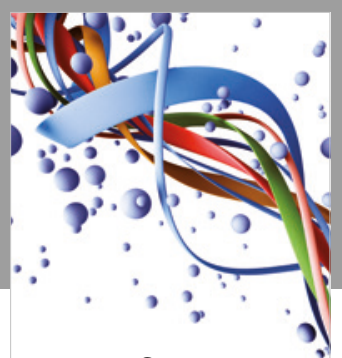

Scientifica

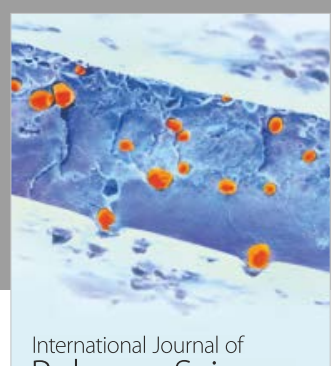

Polymer Science

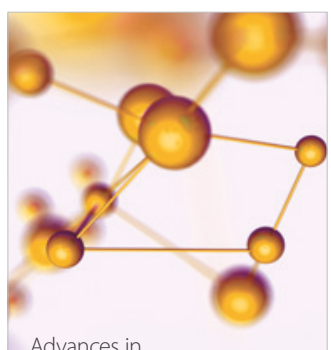

Physical Chemistry
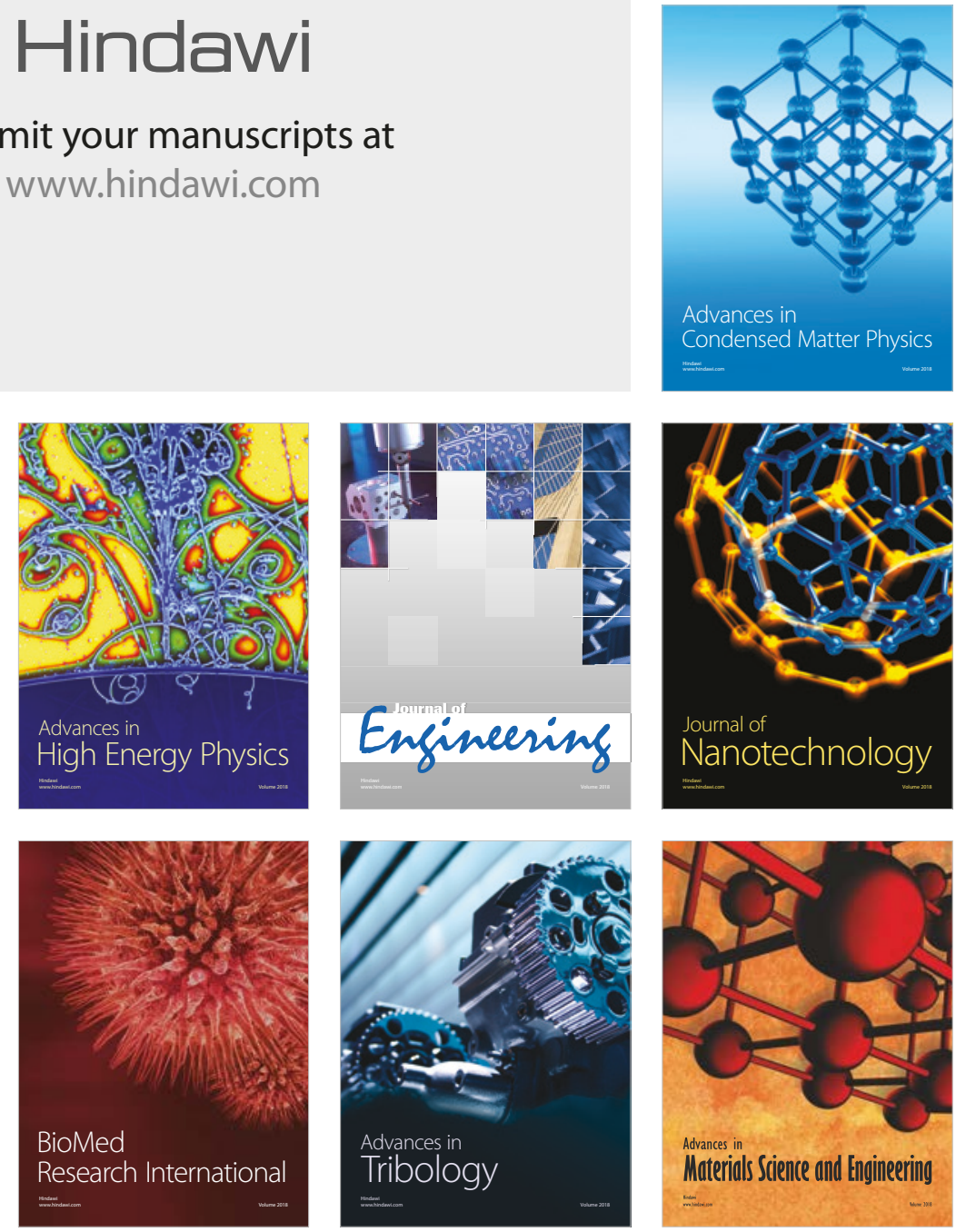